\title{
Evaluation of screw placement in proximal humerus fractures regarding drilling manoeuvre and surgeon's experience ${ }^{\text {it }}$
}

\author{
Gloria Maria Hohenberger ${ }^{a}$, Angelika Maria Schwarz ${ }^{\mathrm{b}}$, Jan Dauwe ${ }^{\mathrm{c}, *}$, Peter Grechenig ${ }^{\mathrm{d}}$, \\ Mario Staresinic ${ }^{e}$, Georg Feigl ${ }^{\mathrm{f}}$, Bore Bakota ${ }^{\mathrm{g}}$ \\ a Department of Orthopaedics and Trauma Surgery, Medical University of Graz, Austria \\ ${ }^{\mathrm{b}}$ AUVA Trauma Hospital Graz, Austria \\ ${ }^{\mathrm{c}}$ Department of Orthopaedics and Trauma Surgery, University Hospitals Leuven, Herestraat 49, 3000 Leuven, Belgium \\ ${ }^{\mathrm{d}}$ Medical University of Graz, Austria \\ e Department of Traumatology, Clinical Hospital Merkur, Zagreb, Croatia \\ ${ }^{\mathrm{f}}$ Institute of Anatomy, Medical University of Graz, Austria \\ ${ }^{\mathrm{g}}$ Department of Traumatology, Landesklinikum Horn, Austria
}

\section{A R T I C L E I N F O}

\section{Article history:}

Accepted 21 February 2020

\section{Keywords:}

Proximal humeral plate osteosynthesis

Proximal humeral fracture

Drilling

PHILOS plate

\begin{abstract}
A B S T R A C T
Introduction: Following proximal humeral plate osteosynthesis, mechanical complication rates ranging up to $40 \%$ have been reported. The study aims to determine the influence of surgeons' experience and the technique of drilling on the complication rate.

Materials and Methods: The sample involved 45 cadaveric humeri. Six orthopaedic surgeons were divided into two groups with regard to their level of experience (novice versus expert group). On each humerus two different proximal humerus plates were applied. Drillings were performed either with a sharp or worn drill bit (to simulate either sharp or blunt drilling). The respective holes were drilled until the respective participant thought to have placed the drill bit subchondrally, followed by perforation of the cartilage of the humeral head. Both these values and cases of unintended penetration of the articular cavity were evaluated.

Results: Fourteen holes (3.6\%) were primary penetrated in the joint cavity in the worn-drill-bit-subgroup and 19 holes (5\%) in the sharp-drill-bit-group. The latter had an average distance between the chosen subchondral position and the humeral articular surface of $8.3 \mathrm{~mm}$ and the worn-drill-bit-subgroup was at $10.6 \mathrm{~mm}$. In the novice group 20 perforations (5.2\%) of the joint space occurred and the mean interval between the chosen subchondral point and the humeral articular surface was $4.0 \mathrm{~mm}$. The experienced surgeons showed a perforation rate of $3.4 \%$ and were at a mean of $14.9 \mathrm{~mm}$. There were no significant differences regarding drilling manoeuvres and experience.

Conclusion: Although our results are satisfactory, they can be traced back to the relatively high interval between the respective chosen position of the drill bit and the humeral articular surface which may not guarantee screw stability during ORIF of all fracture patterns.
\end{abstract}

(c) 2020 Elsevier Ltd. All rights reserved.

\section{Introduction}

Proximal humerus fractures represent circa $5 \%$ of all fractures, with notable increase of incidence in elderly women [1]. Regarding young patients, they are mostly the result of high-energy traumas, whereas in the older population these fractures occur commonly due to osteoporotic bone constitutions.

\footnotetext{
This paper is part of a supplement supported by The Croatian Trauma Society.

* Corresponding author.

E-mail address: dauwejan@gmail.com (J. Dauwe).
}

The treatment of proximal humerus fractures has been a very moving subject and is still a controversial topic in orthopaedic and trauma surgery. Currently, the literature lacks scientific evidence for the best treatment option. Although most of these fractures are stable and can be treated conservatively [2], a large variety of techniques has been described for their surgical treatment [2-6]. Surgical intervention is recommended for displaced fractures and commonly involves open reduction and internal fixation (ORIF). Unfortunately, clinically relevant complications following this procedure have been described by several authors [7-10]. In order to reduce these complication rates, an anatomically pre- 
shaped proximal humeral internal locking system (PHILOS, Synthes $\mathrm{GmbH}$, Oberndorf, Switzerland) was developed to improve screw fixation in the osteoporotic bone and to minimize soft tissue damage. Stable screw fixation is especially necessary in the osteoporotic bone since osteoporotic fractures tend to be more complex with progress of the disease as postulated by Court-Brown et al. [11]. The PHILOS plate provides angular stability which is especially useful in osteoporotic bone [12] and recently published clinical studies show promising outcomes regarding their use $[13,14]$. Nevertheless, complication rates ranging up to $40 \%$, including postinterventional dislocations as well as loss of reduction and screw perforations have been reported [15].

The aim of this study was to determine the efficacy of proximal humerus plating regarding screw length, over penetration of humeral head, surgeon's experience and different drill techniques in a cadaveric model.

\section{Materials and methods}

\section{Sample composition}

A total of 45 upper extremities from adult human cadavers donated to science, embalmed with Thiels method [16,17], were evaluated. All investigated cadavers were donated to the Department of Macroscopic and Clinical Anatomy of the Medical University of Graz under the approval of the Anatomical Donation Program of the University of Graz and according to the Austrian law for donations. The collective consisted of 22 limbs from female and 23 upper extremities from male donors. Their age ranged from 57 to 93 years with a median of 74 years. Via inspection of the skin and soft tissues as well as through radiographic control with the C-arm ( $\mathrm{Ar}$ cadis@ Orbic 3D; Siemens Healthcare Diagnostics GmbH, Erlangen, Germany), extremities with former fractures, surgical interventions or malformations in the region of interest had been excluded prior to the implementation of the study.

\section{Investigators}

A total of six orthopaedic surgeons (4 males, 2 females) participated in the study. All of them were right handed, regarding performance of the same drill technique. The surgeons were divided into two groups with regard to their level of experience. Here, the novice group consisted of three participants with a mean age of 25 years (range: 24-27; two males, one female) and six months to one year of trauma surgery experience. The further three participants (two males, one female) formed the expert group with five up to twenty years of trauma surgery experience and a mean age of 38 years (range 31-50). All participants were aware of the study's purpose aiming subchondral drilling without humeral head perforation.

\section{Study protocol}

After complete soft tissue removal from the bone, humeri showing severe arthrosis were excluded. Next, a PHILOS plate (Synthes $\mathrm{GmbH}$, Synthes $\mathrm{GmbH}$, Oberdorf, Switzerland) and after the first drilling manoeuvre, a HOFER proximal humerus plate (Hofer $\mathrm{GmbH}$, Fürstenfeld, Austria) were applied as recommended by the company. Since these two locking plates have different and not overlapping patterns of screw hole positioning, both could be used in succession on each humerus. The plates were temporary fixed to the bone with two 2-mm K-wires. As the next step, a pre-shaped polystyrene plate was mounted to the bone's articular surface to simulate the joint cavity. All drilling procedures were performed by use of a $2.5 \mathrm{~mm}$ drill bit with a Colibri II (Synthes $\mathrm{GmbH}$,

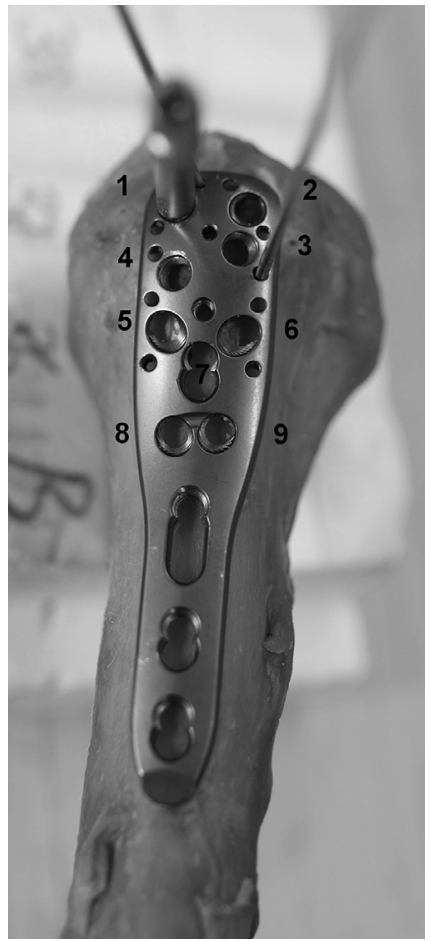

Fig. 1. Numeration of a fixed PHILOS proximal humerus plate.

Oberndorf, Switzerland) in an oscillating manner. Here, the investigators were advised to drill perpendicular to the bone and to avoid penetration of the glenohumeral joint. Afterwards, the first hole was drilled until the respective investigator thought to have placed the drill bit subchondrally. This value was then measured using a depth gauge in millimetres. Afterwards, penetration of the joint space was conducted and this distance was additionally measured. This procedure was performed for all of each plate's holes. The defined drilling sequence with numbered holes of both plates can be seen in Figs. 1 and 2. Further, cases of unattended penetration of the simulated joint space as well as the fact that this was noticed by the respective participant were also recorded. Additionally, in one half of the applied plates, drilling was performed with a sharp drill bit and in the further specimens drilling by use of a worn drill (to simulate blunt drilling) bit was performed. All drill bits were replaced following the processing of three humeri in order to obtain sharp drill bits. All the procedures were monitored and supervised by one of the investigators regarding perforation of the simulated joint cavities (G.H).

\section{Statistical analysis}

Statistical analysis was performed by an independent, blinded person. SAS software (version 9.4; SAS Institute, Inc., Cary, NC, USA) was used for the statistical analysis and a p-value $<0.05$ was considered significant. Categorical data are represented as frequencies and percentages; continuous variables are represented as mean, standard deviation (SD), median, minimum and maximum. The frequencies of the perforations of the simulated joint space were tested for significance with Fisher's exact test. A linear mixed model was used to determine differences in the screw length on the positions, separately for each locking plate. The influence of the different drill techniques (sharp and worn drill bits, respectively) and experience were part of the model, but are not of main interest in this paper. The data was logarithmized before it was used in the model, due to a lack of normal distribution. Because the orthopaedic surgeons performed the procedure several times, 


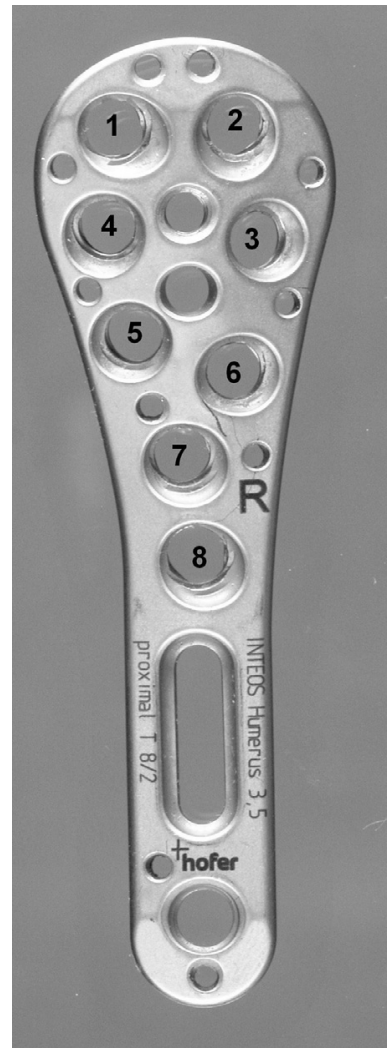

Fig. 2. Numeration pattern of a Hofer plate.

resulting in dependent data, they were regarded as a random effect. Position, drill techniques, experience and all possible interactions between these three variables were used as fixed effects. After model building, the final model included position, drill technique and experience as fixed effects. After Bonferroni correction, the differences between the positions were considered significant at a p-value $<0.02$.

\section{Results}

In total, 46 PHILOS and 44 Hofer plates were tested. Hereof, 45 were performed by use of a sharp ( 381 plate holes) and 45 with a worn drill bit (385 plate holes). Further, 45 were tested by the experienced surgeons and 45 by the novice group. Regarding the joint perforation rate, 14 holes (3.6\%; total collective: 385 holes) were primary penetrated in the subgroup who used the worn drill bits and in 19 holes (5\%; total collective: 381 holes) the simulated joint was perforated in the group that practiced with the sharp drill bits (see Table 1). After exclusion of the perforated holes, the worn-drill-bit-subgroup had an average distance between the chosen position and the articular surface of $10.6 \mathrm{~mm}$ (SD 10.5; median: 4.3; range: 1.9-38.0) and the group that had utilised the sharp drill bit had a mean of $8.3 \mathrm{~mm}$ (SD 7.8; median: 4.4; range: 2.1-29.9).

With regard to the novice group (in total: 384 drilled holes) 20 perforations (5.2\%) of the articular cavity occurred. However, the experienced surgeons (in total: 382 holes) showed a hit rate of $3.4 \%$ (13 holes). After excluding the perforated holes, the unexperienced collective had a mean interval between the chosen point and the humeral articular surface of $4.0 \mathrm{~mm}$ (SD 1.4; median: 3.8; range: 2.1-9.2) and the experienced surgeons were at a mean of $14.9 \mathrm{~mm}$ (SD 10.6; median: 14.4; range: 1.9-38.0).

Fisher's exact test did not show statistically significant differences regarding drilling manoeuvres $(p=0.495)$ and experience
Table 1

Depiction of the results.

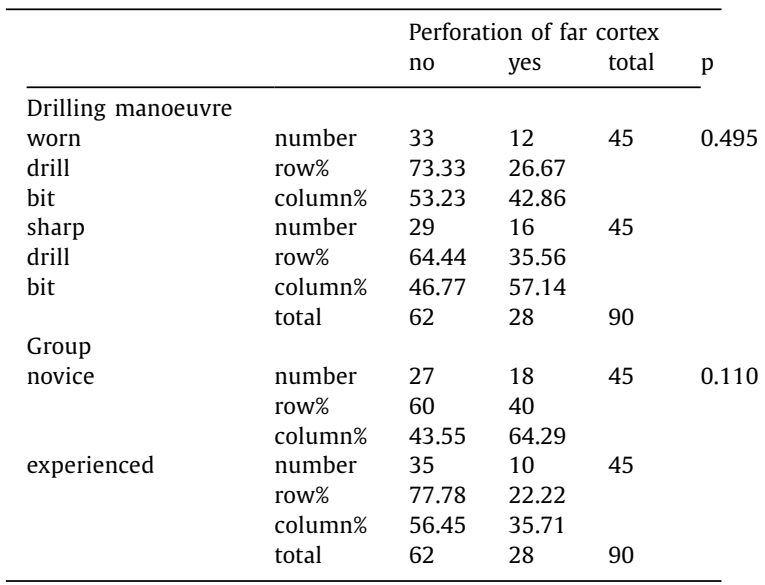

$(p=0.110)$. Regarding unattempted perforation of the articular cavity, this was always noticed by the respective participants except in two cases which were conducted by surgeons from the novice group.

With respect to the mean interval between the humeral articular surface and the chosen screw position, this distance was significantly smaller between screw position 1 in comparison positions $7(p=<0.001)$ and $8(p=0.0007)$ as well as between position 2 compared to positions $7(p=<0.001)$ and $8(p=<0.001)$ in the Hofer sample. However, the PHILOS subgroup did not reveal significant differences between the single screw positions.

\section{Discussion}

Diverse traumas following drilling beyond the far cortex including vascular lacerations [18], tendon ruptures [19] and pseudoaneurysms $[20,21]$ have been described in the literature for both the upper and lower extremities. During proximal humerus plating, the anterior and posterior circumflex humeral arteries as well as the axillary nerve (AN) represent potential structures at risk. Regarding the latter, palsies of the nerve after ORIF have been described [22] and during a cadaver study, Křivohlávek and colleagues [23] located the AN above the insertion points for the screws which are directed to the medial calcar region in $80 \%$ of all cases. Further on, screw augmentation by use of polymethylmetacrylat cement for the enhancement of implant purchase has become very popular in the recent years especially in the osteoporotic bone. Here, biomechanical trials stated that implant augmentation increases its anchorage [24]. However, perforation of the humeral articular surface needs to be absolutely avoided in cases of planned screw augmentation to prohibit cement insertion into the glenohumeral joint.

Primary and secondary intraarticular screw penetration represents one of the main problems following ORIF of proximal humerus fractures. Here, primary screw penetration is defined as the unrecognised intraoperatively performed perforation and the secondary form as a late result of humeral head collapse. In a systematic review, Sproul et al. [25] found screw perforation of the glenohumeral joint with a mean rate of $7.5 \%$ to be the most common reason for early revision surgery. Solberg et al. [26] noted a similar value (7\%) in a retrospective evaluation of 77 patients treated with fixation via locking plates for Neer 3- or 4-part proximal humerus fractures. All of these underwent revision surgery within the first 48 postoperative hours. Further on, Sudkamp and colleagues [9] observed a humeral head perforation rate of even 
14\% in a trial including 155 patients treated with ORIF of the proximal humerus.

These complications may be traced back to insufficient intraoperative drilling and estimation of the respective screw length. Regarding our collective, perforation of the articular cavity occurred in $3.6 \%$ in the subgroup that used the worn drill bits and in 5\% in the group that practiced with the sharp drill bits. Further, the novice group penetrated the articulation in $5.2 \%$ and the experienced subgroup showed a penetration rate of $3.4 \%$. The statistical analysis did not reveal significant differences regarding drilling by use of sharp in comparison to worn drill bits and experienced and unexperienced surgeons. Thus, in comparison to the mentioned studies, we observed a lower perforation rate. Further, our results confirmed Clement et al. [27] outcomes who observed no difference between experienced and unexperienced surgeons regarding overpenetration of the far cortex in a laboratory study during which 153 participants performed drilling manoeuvres on synthetic bones.

Regarding the distance between the chosen maximum drilling position and the articular surface, the worn-drill-bit-subgroup had a mean of $10.6 \mathrm{~mm}$ and the sharp-drill-bit-group had a mean of $8.3 \mathrm{~mm}$. The novice group was at an average of $4.0 \mathrm{~mm}$ and the experience collective showed a mean of $14.9 \mathrm{~mm}$. However, the optimal screw position is recommended to be placed as subchondrally as possible to guarantee optimal screw stability, especially in fractures with thin fracture segments of the humeral calotte. Our collective showed relatively high values, whereas the novice group tended to drill closer to the articular surface in comparison to the experienced group. This fact might possibly be traced back to higher awareness of experienced surgeons regarding possible complications of articular perforation.

Concerning differences between the single screw positions, statistical analysis did not reveal differences for the PHILOS plate. However, in the Hofer plate, positions 1 and 2 showed significantly shorter intervals between the chosen screw position and the humeral articular surface in comparison to positions 7 and 8, respectively. Here, Scola et al. [28] evaluated the local bone quality of the proximal humerus in 44 specimens and found the highest density in the postero-medial region. Since screw positions 1 and 2 of the Hofer plate aim the posterior region, our drilling manoeuvres may have resulted in satisfactory stability regarding these positions.

As a limitation of our study, the awareness if the drill bit had perforated the articular cavity or not could not be optimally evaluated since drillings were performed on humeri which were placed on a polystyrene material. This can hardly be compared to the intraoperative situation. Another disadvantage was the fact that we used intact bones which enables easier plate fixation in comparison to ORIF of fractured proximal humeri.

In our collective, the perforation rate of the articular cavity ranged from $3.4 \%$ (experienced group) to $5.2 \%$ (novice group). Although these results are satisfactory, they can be traced back to the relatively high interval between the respective chosen position and the humeral articular surface which may not guarantee screw stability during ORIF of all fracture patterns.

\section{Informed consent}

Body donors gave their written informed consent during their lifetime.

\section{Funding}

This research did not receive any specific grant from funding agencies in the public, commercial, or not-for-profit sectors.

\section{Disclosure}

This paper is part of a supplement supported by The Croatian Trauma Society.

\section{Declaration of Competing Interest}

All authors declare that they have no conflict of interest.

\section{References}

[1] Court-Brown CM, Caesar B. Epidemiology of adult fractures: a review. Injury 2006;37:691-7. doi:10.1016/j.injury.2006.04.130.

[2] Young TB, Wallace WA. Conservative treatment of fractures and fracture-dislocations of the upper end of the humerus. J Bone Joint Surg Br 1985;67:373-7.

[3] Park MC, Murthi AM, Roth NS, Blaine TA, Levine WN, Bigliani LU. Two-par and three-part fractures of the proximal humerus treated with suture fixation. J Orthop Trauma 2003;17:319-25.

[4] Ogiwara N, Aoki M, Okamura K, Fukushima S. Ender nailing for unstable surgical neck fractures of the humerus in elderly patients. Clin Orthop Relat Res 1996;330:173-80.

[5] Resch H, Povacz P, Fröhlich R, Wambacher M. Percutaneous fixation of three- and four-part fractures of the proximal humerus. J Bone Joint Surg $\mathrm{Br}$ 1997;79:295-300

[6] Robinson CM, Page RS, Hill RM, Sanders DL, Court-Brown CM, Wakefield AE. Primary hemiarthroplasty for treatment of proximal humeral fractures. J Bone Joint Surg Am 2003;85-A:1215-23.

[7] Aggarwal S, Bali K, Dhillon MS, Kumar V, Mootha AK. Displaced proximal humeral fractures: an Indian experience with locking plates. J Orthop Surg Res 2010;5:60. doi:10.1186/1749-799X-5-60.

[8] Thalhammer G, Platzer P, Oberleitner G, Fialka C, Greitbauer M, Vécsei V. Angular stable fixation of proximal humeral fractures. J Trauma 2009;66:204-10. doi:10.1097/TA.0b013e31815ede7b.

[9] Südkamp N, Bayer J, Hepp P, Voigt C, Oestern H, Kääb M, Luo C, Plecko M Wendt K, Köstler W, Konrad G. Open reduction and internal fixation of proximal humeral fractures with use of the locking proximal humerus plate. Results of a prospective, multicenter, observational study. J Bone Joint Surg Am 2009;91:1320-8. doi:10.2106/JBJS.H.00006.

[10] Meier RA, Messmer P, Regazzoni P, Rothfischer W, Gross T. Unexpected high complication rate following internal fixation of unstable proximal humerus fractures with an angled blade plate. J Orthop Trauma 2006;20:253-60.

[11] Court-Brown CM, Garg A, McQueen MM. The epidemiology of proximal humeral fractures. Acta Orthop Scand 2001;72:365-71. doi:10.1080 000164701753542023.

[12] Björkenheim JM, Pajarinen J, Savolainen V. Internal fixation of proximal humeral fractures with a locking compression plate: a retrospective evaluation of 72 patients followed for a minimum of 1 year. Acta Orthop Scand 2004:75:741-5

[13] Bandalović A, Cukelj F, Knežević J, Ostojić M, Pavić A, Parać Z, Rošin M. The results of internal fixation of proximal humeral osteoporotic fractures with PHILOS locking plate. Psychiatr Danub 2014;26(Suppl 2):376-81.

[14] Kim JJ, Kim JW, Yu HS, Lee HS, Oh HK. Factors affecting accurate drill sleeve insertion in locking compression plates. Orthop Traumatol Surg Res 2013;99:823-7. doi:10.1016/j.otsr.2013.04.013.

[15] Kumar GN, Sharma G, Sharma V, Jain V, Farooque K, Morey V. Surgical treatment of proximal humerus fractures using PHILOS plate. Chin J Traumatol 2014; 17:279-84.

[16] Thiel W. An arterial substance for subsequent injection during the preservation of the whole corpse. Ann Anat 1992;174:197-200.

[17] Thiel W. The preservation of the whole corpse with natural color. Ann Anat 1992;174:185-95.

[18] Johnson B, Thursby P. Subclavian artery injury caused by a screw in a clavicular compression plate. Cardiovasc Surg 1996;4:414-15.

[19] Al-Rashid M, Theivendran K, Craigen MA. Delayed ruptures of the extensor tendon secondary to the use of volar locking compression plates for distal radial fractures. J Bone Joint Surg Br 2006;88:1610-12. doi:10.1302/0301-620X. 88B12.17696.

[20] Manner M, Rösch B, Roy K. Vascular injuries complicating osteosynthesis in proximal femur fractures. Unfallchirurg 1999;102:227-31.

[21] O'Connor JV, Stocks G, Crabtree Jr JD, Galasso P, Wallsh E. Popliteal pseudoaneurysm following total knee arthroplasty. J Arthroplasty 1998;13:830-2.

[22] Thalhammer G, Platzer P, Oberleitner G, Fialka C, Greitbauer M, Vécsei V. Angular stable fixation of proximal humeral fractures. J Trauma 2009;66:204-10. doi:10.1097/TA.0b013e31815ede7b

[23] Křivohlávek M, Taller S, Lukáš R, Dráč P. Anatomy notes on minimally invasive plate osteosynthesis of the proximal humerus. A cadaver study. Acta Chir Orthop Traumatol Cech 2014;81:63-9.

[24] Unger S, Erhart S, Kralinger F, Blauth M, Schmoelz W. The effect of in situ augmentation on implant anchorage in proximal humeral head fractures. Injury 2012;43:1759-63. doi:10.1016/j.injury.2012.07.003.

[25] Sproul RC, Iyengar JJ, Devcic Z, Feeley BT. A systematic review of locking plate fixation of proximal humerus fractures. Injury 2011;42:408-13. doi:10.1016/j. injury.2010.11.058. 
[26] Solberg BD, Moon CN, Franco DP, Paiement GD. Locked plating of 3- and 4Part proximal humerus fractures in older patients: the effect of initial fracture pattern on outcome. J Orthop Trauma 2009;23:113-19. doi:10.1097/BOT. 0b013e31819344bf.

[27] Clement H, Heidari N, Grechenig W, Weinberg AM, Pichler W. Drilling, not a benign procedure: laboratory simulation of true drilling depth. Injury 2012;43:950-2. doi:10.1016/j.injury.2011.11.017.
[28] Scola A, Gebhard F, Weckbach S, Dehner C, Schwyn R, Fliri L, Röderer G. Mechanical quantification of local bone quality in the humeral head: a feasibility study. Open Orthop J 2013;7:172-6. doi:10.2174/1874325001307010172. 